\title{
PENGARUH MODEL SELF DIRECTED LEARNING TERHADAP HASIL BELAJAR SISWA PAI PADA MASA PANDEMI
}

\author{
Tri Wulandari* \\ Gunawan Ikhtiono, Salati Asmahasanah \\ Universitas Ibn Khaldun Bogor, Indonesia \\ *E-mail:tri800407@gmail.com
}

\begin{abstract}
The application of the self-directed learning model in the learning process that prioritizes students' independence, activeness and responsibility to obtain improved learning outcomes, either from students' understanding, attitudes or skills. This study aims to determine the average control and experimental classes and determine the effect of the application of the model. The research method used is a quasi-experimental method, providing an overview of student learning outcomes and the influence of the applied model. The results showed that: 1) the average learning outcomes of the experimental class using the self-directed learning model in the cognitive aspect was 84.75 and the affective aspect was 80.19. 2) there is a significant influence between the self-directed learning model on the learning outcomes of Islamic Religious Education (PAI) students in the cognitive aspect. There is also a significant influence between the self-directed learning model on PAI student learning outcomes in the affective aspect. This self-directed learning model can be used as an alternative for teachers in the $P A I$ learning process.
\end{abstract}

Keywords: Self Directed Learning model, learning Outcomes, Islamic Education

\begin{abstract}
Abstrak. Penerapan model self directed learning pada proses pembelajaran yang mengutamakan kemandirian, keaktifan dan tanggung jawab siswa sehingga memperoleh hasil belajar yang meningkat baik dari pemahaman, sikap maupun keterampilan siswa. Penelitian ini bertujuan untuk mengetabui rata-rata kelas kontrol dan eksperimen serta mengetabui pengaruh penerapan model tersebut. Metode penelitian yang digunakan adalah metode kuasi eksperimen, memberikan gambaran hasil belajar siswa dan pengaruh dari model yang diterapkan. Hasil penelitian menunjukkan bahwa: 1) rata-rata hasil belajar kelas eksperimen dengan menggunakan model Self directed learning pada aspek. kognitif sebesar 84,75 dan pada aspek afektif sebesar 80,19. 2) terdapat pengaruh yang signifikan antara model Self directed learning terhadap hasil belajar siswa Pendidikan Agama Islam (PAI) pada aspek kognitif. Kemudian terdapat pengaruh yang signifikan antara model Self directed learning terhadap hasil belajar siswa PAI pada aspek afektif. Model self directed learning ini dapat dijadikan alternatif guru dalam proses pembelajaran PAI.
\end{abstract}

Kata Kunci Self Directed Learning, Hasil Belajar, Pendidikan Agama Islam 


\section{PENDAHULUAN}

Pendidikan merupakan kebutuhan primer bagi kehidupan manusia, sehingga meningkatkan kehidupan yang beradab dan bernilai. Pendidikan juga merupakan proses kumpulan aktivitas yang membentuk manusia yang dapat bermanfaat bagi dirinya, masyarakat hingga Negara. Semua proses pendidikan seorang individu pasti mengalami berbagai kondisi yang harus dilalui, terutama saat ini yang menerapkan pembelajaran jarak jauh, dikarenakan adanya penyebaran COVID-19 yang masih tinggi.

Kementerian Pendidikan dan kebudayaan (Kemendikbud) masih menetapkan proses pembelajaran jarak jauh pada tahun ajaran 2020-2021. Pasalnya, penyebaran COVID-19 yang masih cukup tinggi membuat pemerintah masih menutup sekolah dan dialihkan semua online. Lalu, pemerintah mengambil dua cara program belajar selain tatap muka. Dua cara yang diambil untuk melakukan pembelajaran jarak jauh (PJJ), yakni para peserta didik belajar melalui sarana televisi maupun secara daring (Sandro, 2021:1).

Dengan hal itu, semua tingkat pendidikan secara nasional baik level dasar, menengah sampai perguruan tinggi masih menggunakan pembelajaran jarak jauh sebagai alternatif di masa pandemi saat ini. Menurut Undang-Undang Nomor 20 tahun 2003 tentang Sistem Pendidikan Nasional (SISDIKNAS), "Pendidikan Jarak Jauh (PJJ) yakni pendidikan yang memberikan layanan kepada masyarat yang tidak bisa mengikuti secara tatap muka atau regular" (Depdiknas, 2003:12). Sehingga, para guru dituntut untuk kreatif dan inovatif dalam menyajikan pembelajaran kepada peserta didik, agar pembelajaran dapat menyenangkan dan peserta didik dapat memahami pembelajaran dengan baik dan benar.

Berbagai cara dilakukan agar pembelajaran berlangsung dengan efektif dan efisien, maka guru menggunakan berbagai model pembelajaran. "Model pembelajaran ialah rangkaian pembelajaran yang tergambar dari awal hingga selesai pembelajaran yang diberikan secara khas oleh guru. Dengan kata lain, model pembelajaran merupakan induk dari penerapan suatu pendekatan, metode, strategi, dan teknik pembelajaran" (Helmiati, 2012:19).

"Model pembelajaran dapat dijadikan beberapa pola yang dapat dipilih, maksudnya guru dapat memilih pola atau model yang sesuai dan efisien untuk mencapai tujuan yang telah direncanakan" (Nurdyansyah, 2016:20). Sehingga guru perlu memperhatikan model pembelajaran yang akan dipilih dengan tujuan yang sudah rancang, sehingga dapat tersusun dengan baik dalam proses pembelajaran yang berlangsung.

Setiap model memiliki tujuannya agar memberikan efek positif bagi siswa untuk memahami apa yang dibutuhkan dan menumbuhkan rasa ingin tahu yang tinggi saat menjangkau berbagai informasi yang dicari, seperti salah satunya model self directed learning. Menurut Long dalam Rasyid (2019:91). "self directed learning yaitu proses mental yang disertai dengan proses perilaku yang tampak seperti menganalisis masalah dan pencarian informasi”.

Dalam proses penilaian baik sebelum, saat maupun setelah pembelajaran 
berlangsung, hasil belajar siswa menjadi tolak ukur dalam mengetahui tingkat pemahaman siswa dan keberhasilan dalam proses pembelajaran. "hasil belajar merupakan perubahan tingkah laku yang meningkat atau menurun sesuai dengan hasil dari proses belajar. Perubahan yang dimaksud dapat dilihat dari ranah pengetahuan, pemahaman, keterampilan dan sikap yang biasanya meliputi ranah kognitif, afektif, dan psikimotorik" (Husamah, 2016:31). Mengevaluasi siswa tentu harus sesuai indikator yang akan dicapai, kemudian indikator tersebut dibentuk menjadi instrumen soal melalui tes, lalu dibagikan kepada siswa baik di awal (pretest) maupun di akhir (post test) pembelajaran, sehingga menghasilkan jawaban siswa yang akan menjadi tolak ukur keberhasilan suatu pembelajaran.

Kemudian, Bagi peserta didik sendiri, sistem penilaian yang baik akan mampu memberikan motivasi untuk selalu meningkatkan kemampuannya. Dalam sistem evaluasi hasil belajar, "penilaian merupakan tahapan berikutnya setelah dilakukan pengukuran. Hasil yang diperoleh dari proses pengukuran, kemudian dijelaskan detail dan dianalisis" (Widiyanto, 2018:7). Sehingga dari hasil belajar yang dideskripsikan dan dianalisis oleh guru serta dapat diambil kesimpulan terkait keefektifan model pembelajaran yang diterapkan kepada siswa termasuk penerapan model self directed learning dalam pembelajaran jarak jauh tersebut.

Penggunaan model pembelajaran memang harus disesuaikan dengan materi ajar yang akan disampaikan, termasuk pada pembelajaran PAI. "proses pembelajaran PAI adalah upaya sadar dalam mempersiapkan peserta didik untuk mengetahui, memahami, menghayati, hingga mengimani ajaran agama Islam, bersamaan dengan tuntutan untuk toleransi terhadap agama lain dalam interaksinya dengan kerukunan antar umat manusia hingga tercapai kesatuan dan persatuan bangsa" (Ernanida, 2019:103). Maka dari itu, tujuan dari PAI tidak hanya sebatas siswa memahami materi yang sudah dipelajari, namun memberikan kematangan dalam keimanan, keilmuan dan pengamalan pada diri siswa yang lebih baik.

Peneliti mengamati saat Praktek Profesi Keguruan (PPK) PAI di Sekolah Menengah Atas Negeri 1, sebagian peserta didik merasa jenuh, ditambah dengan metode ceramah variasi saja dalam proses pembelajaran jarak jauh dan sebagian peserta didik yang tidak mengumpulkan tugas dengan alasan lupa, kemudian tidak menanyakan kembali kepada guru, terkait materi atau tugas yang sudah diberikan, sehingga hasil belajar sebagian siswa pun kurang memuaskan.

Maka peneliti mencoba memberikan treatment di dalam proses pembelajaran daring melalui penerapan model self directed learning dan dikaitkan dengan hasil belajar siswa. Maka dari latar belakang di atas dapat dirumuskan yaitu berapa ratarata dari kelas eksperimen dengan kelas kontrol dan adakah pengaruh penerapan model self directed learning terhadap hasil belajar siswa PAI di SMAN 1 Kota Bogor dengan model konvensional?

\section{METODE PENELITIAN}

Metode yang digunakan dalam penelitian ini adalah jenis eksperimen quasi. Penelitian ini dilakukan menggunakan 
dua kelompok yang diberikan perlakuan berbeda, yakni kelas kontrol dan kelas eksperimen (Juwaeriah, 2017:82). Kelas kontrol diberikan perlakuan dengan metode konvensional, sedangkan kelas eksperimen menggunakan metode self directed learning (SDL).

Instrumen yang digunakan ada dua bagian, yaitu tes dan non tes. Tes berupa hasil belajar yang digunakan adalah berupa soal pilihan ganda untuk mengukur kognitif siswa. Kemudian, non tes berupa skala likert untuk mengukur hasil belajar afektif siswa.

\section{Populasi}

Menurut Arikunto (2014:173) populasi adalah seluruh subjek penelitian, jika seseorang ingin meneliti maka semua elemen yang ada dalam wilayah penelitian. Adapun populasi dalam penelitian ini adalah seluruh peserta didik kelas $\mathrm{X}$ SMAN 1 Kota Bogor.

\section{Sampel}

Sampel adalah bagian dari populasi yang sudah ditentukan. Sampel ini merupakan sebagian atau perwakilan dari populasi sedang diteliti (Arikunto, 2014:174). Teknik sampling yang digunakan dalam penelitian ini adalah teknik purposive sampling. Sugiyono, (2019:153) mengemukakan bahwa teknik purposive sampling adalah teknik penentuan sampel dengan pertimbangan tertentu. Adapun sampel dalam penelitian ini adalah peserta didik kelas $\mathrm{X}$ MIPA 5 sebagai kelas kontrol dan X MIPA 6 sebagai kelas Eksperimen.

\section{Self Directed Learning}

Menurut Dickinson dalam Huda, (2013:263) self directed learning adalah model dengan kondisi di mana pembelajar memiliki kontrol seluruhnya dalam proses keputusan dalam proses pembelajaran itu sendiri dan menerima tanggung jawab sepenuhnya, meskipun mereka dan tentu masih membutuhkan bantuan dan nasehat dari seorang guru. Namun, menurut Rusman (2016:377) perlu ditekankan bahwa model self directed learning di dalam program belajar online pada pendidikan formal, tidak sepenuhnya memberikan kepada kemandirian siswa, semisal memutuskan tujuan, sumber dan cara belajar, akan tetapi siswa diarahkan kepada kemandirian dalam kegiatan belajarnya saja.

Maka dapat disimpulkan, self directed learning adalah proses pembelajaran yang mengutamakan kemandirian siswa dan tanggung jawab dalam kegiatan belajar untuk mendapatkan ilmu pengetahuan serta guru sebagai kontrol agar proses pembelajaran sesuai dengan indikator yang sudah ditetapkan.

Menurut Holec dalam Huda, (2013:264-265) dalam model self directed learning, memiliki 4 tahapan pembelajaran yang langkah-langkahnya sebagai berikut:

a. Tahapan perencanaan

1. Menganalisis kebutuhan siswa, sekolah dan kurikulum

2. Menganalisis skill-skill yang dimiliki oleh siswa

3. Merancang dan menetapkan tujuan pembelajaran yang berkelanjutan

4. Memilah sumber daya yang baik dan tepat

5. Membuat konsep perencanaan mengenai aktivitas pembelajaran harian

b. Tahapan Penerapan 
1. Mendiskusikan rencana guru dengan kemampuan siswa

2. Menerapkan hasil rencana yang telah diinovasi dan aturan yang telah dilakukan

3. Memberikan kesempatan siswa untuk memilih metode yang sesuai dengan kebutuhannya.

c. Tahapan Pengawasan

1. Mengawasi siswa selama mengerjakan tugas-tugas pembelajaran.

2. Mengawasi siswa selama mengerjakan aktivitas-aktivitas di luar dari tugas pokok pembelajaran.

d. Tahapan Penilaian

1. Mengevaluasi hasil kerja siswa sebelum dan sesudah

2. Menyesuaikan dan mengevaluasi tugas siswa dengan tujuan yang telah dirancang sebelumnya.

3. Mengajukan pertanyaan pada siswa mengenai proses penyelesaian tugas.

Menurut Uno (2018:52-53) Self Directed Learning (Belajar mandiri) sebagai berikut:

A. Kelebihan Self Directed Learning (Belajar mandiri), yaitu:

1. Belajar mandiri yang dirancang dengan tepat akan memanfaatkan lebih banyak dasar belajar.

2. Model ini memberikan kesempatan bagi siswa, baik kepada siswa yang kurang cepat maupun yang cepat untuk menuntaskan dalam memahami pelajaran.
3. Model ini merangsang rasa percaya diri dan tanggung jawab pada diri siswa.

4. Program belajar mandiri dapat memberikan lebih banyak perhatian tercurah kepada siswa.

5. Ia mempunyai waktu lebih banyak untuk memantau dan mengobservasi siswa dalam pertemuan kelompok dan untuk konsultasi para siswa.

B. Kekurangan Self Directed Learning (Belajar mandiri), yaitu:

1. Memungkinkan kurangnya interaksi antar pengajar dengan siswa atau antar siswa dengan siswa.

2. Apabila hanya digunakan metode satu jalur dengan langkah tidak dinamis, maka kegiatan belajar akan membosankan dan tidak menarik.

3. Program mandiri tidak cocok untuk semua siswa atau semua pengajar.

4. Kurangnya disiplin diri, kemudian bersamaan dengan kemalasan, menyebabkan lamban dalam penyelesaian program oleh beberapa siswa.

5. Metode belajar mandiri menuntut kerja sama dalam perencanaan tim yang rinci di antara staf pengajar yang terlibat.

\section{Hasil Belajar}

Hasil belajar adalah segala macam prosedur yang digunakan untuk mendapatkan informasi mengenai unjuk kerja (Performance) siswa atau seberapa jauh siswa dapat mencapai tujuan-tujuan 
pembelajaran yang telah ditetapkan. Lalu, hasil belajar juga merupakan perolehan dari proses belajar siswa sesuai dengan tujuan pengajaran (ends are being attained) (Purwanto, 2011:45).

Kemudian, hasil belajar merupakan proses perubahan kemampuan intelektual (Kognitif), kemampuan minat atau emosi (afektif) dan kemampuan motorik halus dan kasar (psikomotor) pada peserta didik. Perubahan kemampuan peserta didik dalam proses pembelajaran khususnya dalam satuan pendidikan dasar diharapkan sesuai dengan tahap pekembangannnya yaitu pada tahapan operasional konkrit (Afandi, 2013:5).

Hasil belajar dan penilaian juga dalam proses pembelajaran sangat erat satu sama lain, membantu guru, siswa dan sekolah dalam mencapai tujuan pendidikan. Karena ia merupakan perubahan tingkah laku dari hasil proses kegiatan pembelajaran (Amirudin, 2020:144).

Maka dapat disimpulkan bahwa, hasil belajar adalah perolehan siswa setelah melakukan pembelajaran dan memberikan informasi secara akurat, untuk melihat seberapa jauh keberhasilan proses pembelajaran dalam ketercapaian tujuan-tujuan yang sudah dirancang sebelumnya.

Menurut Siregar (2015:145) ada beberapa tujuan atau fungsi dari evaluasi hasil belajar adalah sebagai berikut:

a. Diagnostik: mengklasifikasi apa saja kesulitan-kesulitan siswa dalam proses belajar, baik terjadi secara keseluruhan pada bidang yang sedang dipelajari maupun bidangbidang tertentu.

b. Seleksi: penentuan untuk memutuskan calon siswa yang diterima di sekolah tertentu dan calon siswa yang tidak dapat diterima. Seleksi yang dilakukan guna mengelompokkan siswa yang memenuhi syarat tertentu ataukah tidak.

c. Kenaikan kelas: evaluasi belajar selama dua semester dengan keterangan naik atau lulus tidaknya siswa setelah menyelesaikan suatu program pembelajaran tertentu dalam bentuk nilai.

d. Penempatan: memposisikan siswa sesuai dengan kemampuan/ potensi.

Menurut teori Gestalt, belajar merupakan suatu proses perkembangan. Artinya bahwa secara fitrah jiwa raga anak mengalami perkembangan dan pertumbuhan. Perkembangan sendiri memerlukan asupan baik yang berasal dari diri anak sendiri maupun pengaruh dari lingkungannya. Berdasarkan teori ini hasil belajar siswa dipengaruhi oleh dua hal, diri sendiri dan lingkungannya. Pertama, diri sendiri; dalam arti pola pikir atau sikap intelektual, motivasi, minat dan kesiapan siswa, baik jasmani maupun rohani. Kedua, lingkungan; sarana dan prasarana, kompetensi guru, kreativitas guru, sumber-sumber belajar, metode serta dukungan lingkungan, keluarga (orang-orang terdekat siswa) (Susanto, 2013:12).

\section{HASIL PENELITIAN DAN PEMBAHASAN}

Penelitian ini bertujuan untuk menganalisis peningkatan hasil belajar siswa pada pembelajaran PAI dengan membandingkan antara kelas yang menggunakan model self directed 
learning dengan kelas yang menggunakan model konvensional. Untuk menganalisis hal tersebut perlu dilakukan pengolahan data dengan menggunakan SPSS. Ada beberapa pengolahan data yang dihasilkan untuk uji statsitik, yaitu uji normalitas kognitif dan afektif, uji homogenitas kognitif dan afektif, uji paired sample $t$ test baik kognitif dan afektif dan uji independent sample test untuk kognitif dan afektif. Berikut hasil penelitian dan pembahasan di bawah ini:

\section{Tabel 1}

Deskriptif Statistik Hasil Belajar

Kognitif

\begin{tabular}{|l|r|r|}
\hline & \multicolumn{1}{|c|}{$\mathrm{N}$} & \multicolumn{1}{c|}{ Mean } \\
\hline $\begin{array}{l}\text { Post Test } \\
\text { Eksperiment }\end{array}$ & 32 & 84.75 \\
\hline $\begin{array}{l}\text { Post Test } \\
\text { Kontrol }\end{array}$ & 32 & 72.13 \\
\hline $\begin{array}{l}\text { Valid N } \\
\text { (listwise) }\end{array}$ & \multicolumn{2}{|c|}{32} \\
\hline
\end{tabular}

Rata-rata nilai kognitif pada kelas eksperimen yaitu sebesar 84,75 dan kelas kontrol sebesar 72.13 .

Tabel 2

Deskriptif Statistik Hasil Belajar Afektif

\begin{tabular}{|l|c|c|}
\hline & $\mathrm{N}$ & Mean \\
\hline $\begin{array}{l}\text { Post Test } \\
\text { Eksperiment }\end{array}$ & 32 & 80.19 \\
\hline $\begin{array}{l}\text { Post Test } \\
\text { Kontrol }\end{array}$ & 32 & 74.03 \\
\hline Valid N & \multicolumn{2}{|c|}{32} \\
\hline
\end{tabular}

Rata-rata nilai afektif pada kelas eksperimen yaitu sebesar 80,19 dan kelas kontrol sebesar 74.03.
Uji Normalitas Hasil Belajar Kognitif

\begin{tabular}{|c|c|c|c|}
\hline & & $\begin{array}{r}\text { Kolmi } \\
\mathrm{Smi}\end{array}$ & $\begin{array}{l}\text { rov- } \\
\mathrm{v}^{\mathrm{a}}\end{array}$ \\
\hline Kelas & & df & Sig. \\
\hline $\begin{array}{l}\text { Hasil } \\
\text { Belajar }\end{array}$ & $\begin{array}{l}\text { PreTest } \\
\text { Eksperimen }\end{array}$ & 32 & 0.070 \\
\hline & $\begin{array}{l}\text { PostTest } \\
\text { Eksperimen }\end{array}$ & 32 & 0.134 \\
\hline & $\begin{array}{l}\text { PreTest } \\
\text { Kontrol }\end{array}$ & 32 & 0.073 \\
\hline & $\begin{array}{l}\text { Post Test } \\
\text { Kontrol }\end{array}$ & 32 & 0.083 \\
\hline
\end{tabular}

Kriteria pengujian yang diambil berdasarkan nilai probabilitas yaitu:

Ho ditolak, jika probabilitas (sig) $>0,05$

Ho diterima, jika probabilitas (sig) $<0,05$

Pre-Test Eksperimen (Self Directed Learning) probabilitas (sig) $0,070>0,05$ sehingga Ho ditolak, maka data berdistribsi normal. Post Test Eksperimen (Self Directed Learning) probabilitas (sig) 0,134 >0,05 sehingga Ho ditolak, maka data berdistribsi normal. Pre-Test Kontrol (Konvensional) probabilitas (sig) 0,073 > 0,05 sehingga Ho ditolak, maka data berdistribsi normal. Post Test Kontrol (Konvensional) probabilitas (sig) 0,083 > 0,05 sehingga Ho ditolak, maka data berdistribsi normal.

\section{Tabel 4}

Uji Normalits Hasil Belajar Afektif

\begin{tabular}{|l|l|r|r|r|}
\hline \multirow{2}{*}{ Kelas } & \multicolumn{3}{|c|}{ Kolmogorov-Smimov } \\
\cline { 2 - 5 } & \multicolumn{2}{|c|}{ Statistic } & \multicolumn{1}{c|}{ df } & \multicolumn{1}{c|}{ Sig. } \\
\hline \multirow{3}{*}{$\begin{array}{l}\text { HasilBehajar } \\
\text { Afektif }\end{array}$} & $\begin{array}{l}\text { Pre Test } \\
\text { Eskperimen }\end{array}$ & 0.154 & 32 & 0.052 \\
\cline { 2 - 5 } & $\begin{array}{l}\text { Post Test } \\
\text { Eksperimen }\end{array}$ & 0.148 & 32 & 0.071 \\
\cline { 2 - 5 } & Pre Test Kontrol & 0.139 & 32 & 0.122 \\
\cline { 2 - 5 } & Post Test Kontrol & 0.150 & 32 & 0.064 \\
\hline
\end{tabular}

Kriteria pengujian yang diambil berdasarkan nilai probabilitas yaitu:

Ho ditolak, jika probabilitas (sig) $>0,05$

\section{Tabel 3}


Ho diterima, jika probabilitas (sig) < 0,05

Pre-Test Eksperimen (Self Directed Learning) probabilitas (sig) 0,052 >0,05 sehingga Ho ditolak, maka data berdistribsi normal. Post Test Eksperimen (Self Directed Learning) probabilitas (sig) 0,071 > 0,05 sehingga Ho ditolak, maka data berdistribsi normal. Pre-Test Kontrol (Konvensional) probabilitas (sig) 0,122 > 0,05 sehingga Ho ditolak, maka data berdistribsi normal. Post Test Kontrol (Konvensional) probabilitas (sig) 0,064 > 0,05 sehingga Ho ditolak, maka data berdistribsi normal.

\section{Tabel 5}

Uji Homogenitas Hasil Belajar Kognitif

\begin{tabular}{|l|l|r|r|r|r|}
\hline \multicolumn{2}{|l|}{} & $\begin{array}{r}\text { Levene } \\
\text { Statistic }\end{array}$ & df1 & df2 & Sig. \\
\hline $\begin{array}{l}\text { Hasil } \\
\text { Belajar }\end{array}$ & $\begin{array}{l}\text { Based on } \\
\text { Mean }\end{array}$ & 2.588 & 3 & 124 & 0.056 \\
\hline
\end{tabular}

Berdasarkan tabel Test of Homogenity of Variance tersebut, diperoleh hasil uji homogenitas (sig) Based on Mean 0,056 > 0,05. Maka dapat disimpulkan bahwa kedua kelas yaitu kelas eksperimen dan kelas kontrol pada hasil belajar kognitif mempunyai varian yang sama atau homogen.

Tabel 6

Uji Homogenitas Hasil Belajar Afektif

\begin{tabular}{|l|l|r|r|r|l|}
\hline \multicolumn{2}{|l|}{} & Levene & \multicolumn{1}{c|}{ dfl } & \multicolumn{1}{c|}{ df2 } & Sig. \\
\hline Hasil & $\begin{array}{l}\text { Based on } \\
\text { Mean }\end{array}$ & 0.332 & 3 & 124 & 0.802 \\
Belajar & & & & \\
\hline
\end{tabular}

Berdasarkan tabel Test of Homogenity of Variance tersebut, diperoleh hasil uji homogenitas (sig) Based on Mean 0,802 > 0,05. Maka dapat disimpulkan bahwa kedua kelas yaitu kelas eksperimen dan kelas kontrol pada hasil belajar afektif mempunyai varian yang sama atau homogen.

\section{Tabel 7}

Paired Sample T Test Kognitif

\begin{tabular}{|c|c|c|c|c|c|c|}
\hline & Paired Diff & rences & \multirow[b]{3}{*}{$\mathrm{t}$} & \multirow[b]{3}{*}{$\mathrm{df}$} & \multirow{3}{*}{$\begin{array}{c}\text { Sig. (2- } \\
\text { tailed) }\end{array}$} \\
\hline & & \multicolumn{2}{|c|}{$95 \%$ Confidence } & & & \\
\hline & & Lower & Upper & & & \\
\hline Pair 1 & \begin{tabular}{|l|} 
Pre Test \\
Eksperim \\
ent - Post \\
Test \\
Eksperim \\
ent
\end{tabular} & -41.300 & -25.575 & -8.673 & 31 & 0.000 \\
\hline Pair 2 & \begin{tabular}{|l|} 
Pre Test \\
Kontrol - \\
Post Test \\
Kontrol
\end{tabular} & -28.671 & -11.829 & -4.904 & 31 & 0.000 \\
\hline
\end{tabular}

Kriteria pengujian adalah sebagai berikut:

Ho ditolak, jika nilai Sig. (2-tailed) $<0,05$ Ho diterima, jika nilai Sig. (2-tailed) > 0,05

Berdasarkan tabel paired sample ttest diatas diperoleh hasil sebagai berikut:

Pada pre-test eksperimen dan posttest eksperimen terdapat hasil yang diperoleh ialah Sig. (2-tailed) $0,000<0,05$ sehingga Ho ditolak, maka terdapat perbedaan rata-rata hasil belajar siswa untuk pre-test eksperimen dengan posttest eksperimen. Sedangkan, pada pre-test kontrol dan post-test kontrol terdapat hasil yang diperoleh ialah Sig. (2-tailed) $0,000<0,05$ sehingga Ho ditolak, maka terdapat perbedaan rata-rata hasil belajar siswa untuk pre-test kontrol dengan posttest kontrol.

\section{Tabel 8}

Paired Sample T Test Afektif 


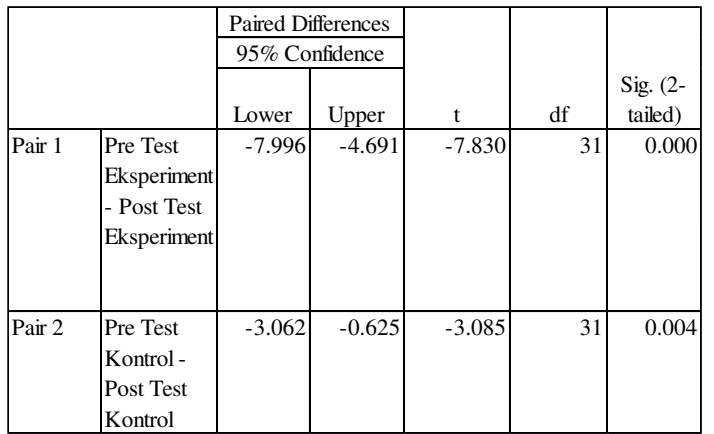

Kriteria pengujian adalah sebagai berikut:

Ho ditolak, jika nilai Sig. (2-tailed) $<0,05$ Ho diterima, jika nilai Sig. (2-tailed) $>$ 0,05

Berdasarkan tabel paired sample ttest diatas diperoleh hasil sebagai berikut:

Pada pre-test eksperimen dan posttest eksperimen terdapat hasil yang diperoleh ialah Sig. (2-tailed) 0,000 < 0,05 sehingga Ho ditolak, maka terdapat perbedaan rata-rata hasil belajar siswa untuk pre-test eksperimen dengan posttest eksperimen. Sedangkan, pada pre-test kontrol dan post-test kontrol terdapat hasil yang diperoleh ialah Sig. (2-tailed) $0,004<0,05$ sehingga Ho ditolak, maka terdapat perbedaan rata-rata hasil belajar siswa untuk pre-test kontrol dengan posttest kontrol.

\section{Tabel 9}

Uji Independent Sample Test Hasil Belajar Kognitif

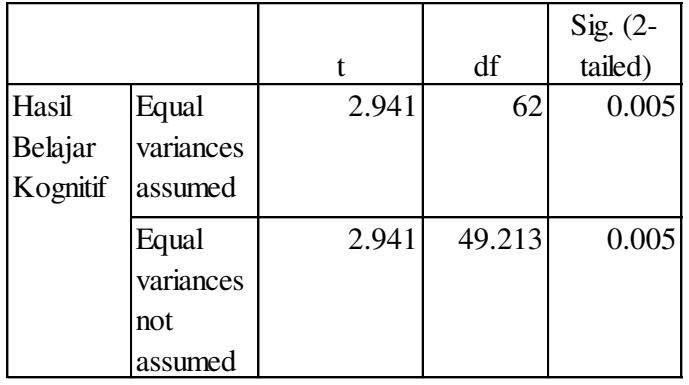

Kriteria pengujian adalah sebagai berikut:

Ho ditolak, jika nilai Sig. (2-tailed) $<0,05$ Ho diterima, jika nilai Sig. (2-tailed) > 0,05

Berdasarkan tabel Independent Samples Test diatas, diperoleh hasil Sig. (2-tailed) $0,005<0,05$. Maka dapat disimpulkan bahwa terdapat pengaruh yang signifikan antara model self directed learning terhadap hasil belajar kognitif pada mata pelajaran Pendidikan Agama Islam.

Tabel 10

Uji Independent Sample Test Hasil Belajar Afektif

\begin{tabular}{|l|l|r|r|r|}
\hline \multicolumn{2}{|c|}{} & \multicolumn{1}{c|}{$\mathrm{t}$} & \multicolumn{1}{c|}{ df } & $\begin{array}{c}\text { Sig. (2- } \\
\text { tailed) }\end{array}$ \\
\hline $\begin{array}{l}\text { Hasil } \\
\text { Belajar } \\
\text { Afektif }\end{array}$ & $\begin{array}{l}\text { Equal } \\
\text { variances } \\
\text { assumed }\end{array}$ & 3.090 & 62 & 0.003 \\
\cline { 2 - 5 } & $\begin{array}{l}\text { Equal } \\
\text { variances } \\
\text { not assumed }\end{array}$ & 3.090 & 57.049 & 0.003 \\
\hline
\end{tabular}

Kriteria pengujian adalah sebagai berikut:

Ho ditolak, jika nilai Sig. (2-tailed) $<0,05$ Ho diterima, jika nilai Sig. (2-tailed) $>$ 0,05

Berdasarkan tabel Independent Samples Test diatas, diperoleh hasil Sig. (2-tailed) $0,003<0,05$. Maka dapat disimpulkan bahwa terdapat pengaruh yang signifikan antara model self directed 
learning terhadap hasil belajar afektif pada mata pelajaran Pendidikan Agama Islam.

\section{KESIMPULAN}

Berdasarkan data dari hasil penelitian yang telah dijelaskan sebelumnya membuktikan bahwa terdapat pengaruh antara penggunaan model self directed learning terhadap hasil belajar Pendidikan Agama Islam pada Masa Pandemi khususnya materi "Menjaga Martabat Manusia dengan Menjauhi Pergaulan Bebas dan Perbuatan Zina". Hal tersebut dapat dibuktikan dari hasil masingmasing kelas baik pada aspek kognitif maupun afektif, sebagai berikut:

1. Rata-rata nilai pada kelas eksperimen yaitu sebesar 84,75 untuk aspek kognitif dan untuk aspek afektif sebesar 80,19. Sementara itu rata-rata nilai pada kelas kontrol yaitu sebesar 72,13 untuk aspek kognitif dan 74,03 untuk aspek afektif.

2. Pengujian melalui Independent Sample $T$ Test diketahui nilai sigifikansi hasil belajar kognitif adalah Sig. (2-tailed) 0,005 $<0,05$ sehingga dapat disimpulkan bahwa terdapat pengaruh yang signifikan antara model Self directed learning terhadap hasil belajar siswa PAI pada aspek kognitif. Kemudian nilai sigifikansi hasil belajar afektif adalah Sig. (2-tailed) 0,003 < 0,05 sehingga dapat disimpulkan terdapat pengaruh yang signifikan antara model Self directed learning terhadap hasil belajar siswa PAI pada aspek afektif.

\section{REFERENSI}

Afandi, M. (2013). Evaluasi Pembelajaran Sekolah Dasar. Semarang: UNISSULA.

Amirudin, \& dkk. (2020). Pengaruh Metode Reward And Punishment Terhadap Hasil Belajar Siswa Pada Bidang Studi Pendidikan Agama Islam (Studi Kasus Di SDIT Tahfizh Qur'an Al-Jabar Karawang). Tarbawy: Indonesian Journal Of Islamic Education, 140-149.

Arikunto, S. (2014). Prosedur Penelitian (Suatu Pendekatan Praktik). Jakarta: Rineka Cipta.

Depdiknas. (2003). Undang-Undang Republik Indonesia Nomor 20 Tahun 2003 Tentang Sistem Pendidikan Nasional. Jakarta: Sekretaris Negara Republik Indonesia.

Ernanida, Y. d. (2019). Media Audio Visual dalam Pembelajaran PAI. Jurnal Pendidikan Islam. Jurnal Pendidikan Islam, 101-112.

Helmiati. (2012). Model Pembelajaran. Yogyakarta: Aswaja Pressindo.

Huda, M. (2013). Model-Model Pengajaran dan Pembelajaran IsuIsu Metodis dan Paradigmatis. Yogyakarta: Pustaka Pelajar.

Husamah, d. (2016). Belajar dan Pembelajaran. Malang: UMM Press.

Juwaeriah, S. M. (2017). Pengaruh Model Pembelajaran Kooperatif Tipe Jigsaw Terhadap Motivasi Belajar Dan Hasil Belajar Siswa Pada Mata Pelajaran Matematika. Attadib Journal of Elementary Education, 78-93. 
Nurdyansyah, d. (2016). Inovasi Model Pembelajaran. Sidoarjo: Nizamia Learning center.

Purwanto. (2011). Evaluasi Hasil Belajar. Yogyakarta: Pustaka Pelajar.

Rasyid, A. (2019). Pengaruh Kompetensi Guru Dan Self Directed Learning Terhadap Hasil Belajar Mata Pelajaran Fikih Pada Siswa Kelas VII MTSN 17 Jakarta Tahun Pelajaran 2018/2019. Jurnal Pendidikan Agama Islam, 89-99.

Rusman. (2016). Model-Model Pembelajaran (Mengembangkan Profesionalisme guru. Jakarta: Rajawali Pers.

Sandro, G. S. (2021, Januari 4). Economic Zone. Retrieved from Economic Zone: http://m.economiczone.id/read/ 1741/kemendikbud-resmibatalkan-belajar-tatap-mukatahun-ajaran-2020-2021.

Siregar, E., \& dkk. (2015). Teori Belajar dan Pembelajaran. Bogor: Ghalia Indonesia.

Sugiyono. (2019). Metode Penelitian Pendidikan (Kuantitatif, Kualitatif, R\&D dan Penelitian Pendidikan. Bandung: Alfabeta.

Susanto, A. (2013). Teori Belajar Pembelajaran di Sekolah Dasar. Jakarta: Prenadamedia Group.

Uno, B. H. (2018). Profesi Kependidikan. Jakarta: Bumi Aksara.

Widiyanto, J. (2018). Evaluasi pembelajaran. Madiun: UNIPMA Press. 